\title{
The relationship between components of metabolic syndrome and plasma level of sex hormone-binding globulin
}

\author{
Amin Alinezhad (1), Fatemeh Jafari (2) \\ (1) Department of Clinical Pharmacy, School of Pharmacy, Tehran University of Medical \\ Sciences, Tehran, Iran; (2) Information Technology Engineering, Qazvin Branch, Islamic Azad \\ University, Qazvin, Iran \\ This article is distributed under the terms of the Creative Commons Attribution Noncommercial License (CC BY-NC 4.0) which permits \\ any noncommercial use, distribution, and reproduction in any medium, provided the original author(s) and source are credited.
}

\begin{abstract}
Plasma concentration of sex hormone-binding globulin (SHBG), as an androgen binding protein, is impressed by many physiological and environmental factors. Recent studies have shown that plasma level of SHBG is related to some components of metabolic syndrome (MetS); however, in contrast, few articles failed to show any associations between SHBG and MetS. So, this study was conducted to investigate the relationship between Components of Metabolic Syndrome and Plasma Level of Sex Hormone-Binding Globulin. In this study, after measuring the plasma level of SHBG in 84 individuals, the relation between MetS and the plasma level of SHBG was investigated. After evaluating the plasma level of SHBG and metabolic abnormalities in men and women, we investigated the factors which mentioned above in two groups including patients with and without MetS. Also, the metabolic abnormalities which evaluated in this study including plasma level of 25-hydroxyvitamin D, serum uric acid (SUA), Albumin, lipid profiles and etc. according to five components of MetS. Our result shows that SHBG could contributed to some laboratory parameters such as LDL-C $(\mathrm{P}<0.05)$, total cholesterol $(\mathrm{P}<0.05)$, triglycerides $(\mathrm{P}<0.05)$ and etc. in men, but not in women. On the other hand, we observed that concentration of SHBG is higher in patients with MetS $(\mathrm{P}<0.05)$; however, results from our experiment showed that there is no relation between lower level of SHBG and five components of MetS such as central obesity, raised fasting plasma glucose (FPG) $(\mathrm{P}>0.05)$, reduced HDL-C $(\mathrm{P}>0.05)$, raised triglycerides $(\mathrm{P}>0.05)$ and raised blood pressure $(\mathrm{P}>0.05)$ in both men and women. There is a significant association between SHBG and Log-Hip Circumference $(\mathrm{P}<0.05)$, Non-HDL-C $(\mathrm{P}<0.05)$ and $\log -25(\mathrm{OH}) \mathrm{D}(\mathrm{P}<0.05)$ was seen in this cross-section study in both men and women. Results obtained from our study suggest that SHBG is not a powerful enough factor to use as a predictor of MetS alone and there is no association between plasma level of SHBG and development of five components of MetS, however, lower SHBG level may contributed to lipid profiles.
\end{abstract}

Key Words: Plasma, Sex Hormone-Binding Globulin, Metabolic Syndrome.

Eur J Transl Myol 29 (2): 143-150, 2019

Sex hormone-binding globulin (SHBG) is a kind of transporter protein in plasma which mostly synthesized in the liver and it could be bind to the androgens such as testosterone, dihydrotestosterone (DHT) and estradiol with various affinities. ${ }^{1}$ Multiple metabolic factors such as sex steroids hormones, prolactin, thyroxine and insulin could impress on the expression of the SHBG in the hepatoma cell line HepG2 of liver. ${ }^{2}$ 1so, molecular studies have suggested that hyperinsulinemia and hyperglycemia could suppresses the expression of SHBG in the liver. ${ }^{3}$ Some epidemiological studies have revealed that plasma level of sex steroid hormones and SHBG are associated with metabolic syndrome (MetS). Many articles have indicated that SHBG levels are related to five metabolic abnormalities of MetS including central obesity, raised FPG, reduced HDL-C, raised triglycerides and raised blood pressure; however, few recent studies have shown that there is no significant relation between SHBG and MetS. ${ }^{4,5}$ Those studies showed the relation between SHBG and MetS, suggested that low concentrations of sex hormones and SHBG in plasma not only contributed to MetS, but also increase the risk of insulin resistance, dyslipidaemia, hypertension and visceral adiposity. Therefore, it could be concluded that sex steroids 


\section{Metabolic Syndrome and Sex Hormone-Binding Globulin}

Eur J Transl Myol 29 (2): 143-150, 2019

hormones and SHBG might play a key role in the pathophysiology of MetS. ${ }^{6}$ In addition, other risk factors including sedentary lifestyle, diet and genetic factors are clearly associated with the MetS. ${ }^{7-9}$ On the other hand, it was suggested that the abnormalities involved in the MetS are highly related with cardiovascular disease (CVD) and type 2 diabetes mellitus (T2DM). ${ }^{10-12}$ Therefore, due to impotence of the MetS and its association with CVD, early diagnosis of MetS is highly suggested. ${ }^{11-13}$ Although the relations between SHBG and MetS have been investigated, the results obtained from past studies are not in line with each other. ${ }^{14-19}$ In the current study, we try to show the relation between SHBG concentration and metabolic abnormalities in both men and women.

\section{Materials and Methods}

We evaluate the plasma level of SHBG and metabolic abnormalities in men and women, then we investigated the factors which mentioned above in two groups including patients with and without MetS. Also, the metabolic abnormalities which evaluated in this study including plasma level of 25-hydroxyvitamin D, serum uric acid (SUA), Albumin, lipid profiles and etc. according to five components of MetS.

\section{Study population}

This is a cross-sectional study. The patients referred to the private endocrinology clinic enrolled for this research.

Inclusion Criteria: 1. had no known history of chronic diseases of heart, lungs, kidneys, or liver.

Exclusion Criteria: has been told by a physician that they had diabetes or were taking anti-hyperglycemic medications at the time of the study.

Between February and May 2016, 84 individuals were enrolled, agreed to participate, and underwent physical examinations and laboratory assessments. All procedures dealing with human subjects where conducted in accordance with the guidelines laid down in the most recent revision of Helsinki declaration. Written informed consent was obtained and recorded for all subjects prior to enrollment.

\section{Interview and physical examination}

At the beginning of study, all subjects were interviewed using a predesigned questionnaire. After obtaining a detailed medical history, a physical examination was conducted by the interviewing physician. Blood pressure was measured using a standard mercury sphygmomanometer (Big Ben adults; Riester, Jungingen, Germany). After 10 minutes of rest, 2 readings of systolic and diastolic blood pressures were taken 5 minutes apart with an appropriately-sized adult cuff, and the average of the 2 readings was recorded. Weight $(\mathrm{kg})$ and height $(\mathrm{cm})$ were measured with the individual wearing only light clothing and no shoes using a calibrated digital scale (GS49; Beurer, Ulm, Germany) and a wallmounted stadiometer, respectively. Body mass index (BMI) was calculated as weight $(\mathrm{kg})$, divided by the height squared (m2). Waist circumference was measured to the nearest $0.1 \mathrm{~cm}$ with an inflexible measuring tape midway between the lowest rib and the iliac crest.

\section{Laboratory Measurements}

Subjects were instructed to complete an overnight fast of 10 to 12 hours and were invited for a blood draw the next morning. In the hospital laboratory, $10 \mathrm{~mL}$ venous blood was drawn, and the following biochemical measurements were performed. FPG was measured using the glucose oxidize method. Fasting insulin (FI) concentrations were measured with an Immunoradiometric assay (Immunotech, Prague, Czech Republic). Homeostatic model assessment of insulin resistance (HOMA-IR), a surrogate index of insulin resistance, was calculated as FPG $(\mathrm{mg} / \mathrm{dl}) \times \mathrm{FI}(\mathrm{IU}) / 405$. The percentage of glycated hemoglobin (HbA1c) was determined using a highperformance liquid chromatography assay.

Serum concentrations of lipids including triglycerides, total cholesterol, and high-density lipoprotein (HDL) cholesterol were measured using enzymatic colorimetric methods (Pars Azmun commercial kits, Karaj, Iran). Serum concentrations of low-density lipoprotein (LDL) cholesterol were determined indirectly using the Friedewald equation. ${ }^{20}$ Serum concentrations of hsCRP were measured using standard kits (Diagnostic Biochem Canada Inc, Dorchester, ON, Canada). Jaffe's kinetic method was used to measure plasma creatinine concentrations. Serum concentrations of SHBG were measured using the enzyme-linked immunosorbent assays. The intra- and inter assay coefficients of variation of the kit (CSB-E08947h, Cusabio, Wuhan, China) were $<8 \%$ and $<10 \%$, respectively.

\section{Definition of MetS}

The diagnosis of MetS was based on the criteria outlined by the International Diabetes Federation (22). Subjects were diagnosed with MetS if they were centrally obese (waist circumference $\geq 90 \mathrm{~cm}$ in both sexes or BMI over $30 \mathrm{~kg} / \mathrm{m} 2$ ), and had at least 2 of the following 4 criteria: (1) raised triglycerides $(\geq 150 \mathrm{mg} / \mathrm{dl})$ or previous hypertriglyceridemia treatment, (2) reduced HDL cholesterol ( $<40 \mathrm{mg} / \mathrm{dl}$ in males and $<50 \mathrm{mg} / \mathrm{dl}$ in females), (3) elevated blood pressure (systolic blood pressure $\geq 130 \mathrm{~mm} \mathrm{Hg}$ and/or diastolic blood pressure $\geq 85 \mathrm{~mm} \mathrm{Hg}$ ) or treatment of previously diagnosed hypertension, and (4) raised FPG (FPG $\geq 100 \mathrm{mg} / \mathrm{dl}$ ) or previously diagnosed type 2 diabetes.

\section{Statistical Analysis}

Statistical analyses were done using Statistical Package for Social Sciences (SPSS) software, version 24.0 (SPSS Inc, Chicago, IL). Continuous variables with normal distributions are presented as mean $\pm \mathrm{SD}$, and those with non-normal distributions are presented as median (interquartile range). Continuous variables with nonnormal distributions (i.e., SHBG) were $\log$ transformed for parametric analyses. Sex, the only categorical 
variable, is presented as a female/male ratio. Continuous variables between individuals with and without MetS were compared with independent $t$ tests. We performed c2 tests to compare the female/male ratio between MetS and non-MetS individuals. Bivariate correlation analysis using Pearson's correlation coefficient was used to determine the degree of association between SHBG and MetS, sex, and laboratory parameters. Analysis of variance (ANOVA) was carried out to investigate the presence of a linear association between log-SHBG and the number of metabolic abnormalities (0 to 5). Uni- and multivariate logistic regression models were used to assess whether log-SHBG concentrations were associated with the presence of each individual component of MetS and also MetS as a single entity. In each model, (odds ratio (OR) 95\% confidence intervals (CI) was calculated per 1-SD increment in the log- 5HIAA values. $P<0.05$ was considered statistically significant for all tests.

\section{Results}

\section{Baseline characteristics of the persons}

A total of 84 persons were enrolled, and $75 \%$ were male. $40 \%$ of male and $10 \%$ of female were diagnosed with MetS. The subjects which are presented in table 1 show baseline characteristics of the population in male and female separately. In the first part of this study, analysis showed that waist-hip ratio (WHR) $(P<0.001)$, Weight $(P<0.05)$, and Waist Circumference $(P<0.05)$ were significantly higher in men when compare to women. Also, Serum concentrations of FPG $(P<0.05)$, 2hPPG $(P<0.05)$, HDL-C $(P<0.05)$, Creatinine $(P<0.001)$, Uric Acid $(P<0.01)$, ALT $(P<0.01)$, the index of HOMA-IR $(P<0.05)$ and percentage of HA1C $(P<0.05)$ were significantly lower in women. On the other hand, plasma level of SHBG $(P<0.05)$ and HDL-C $(P<0.001)$ were significantly higher in women. As shown in table 1 there is no significant differences in serum concentration of

Table 1. Baseline Characteristics of the Population

\begin{tabular}{|l|l|l|l|}
\hline Variable & Men $(n=63)$ & Women $(n=21)$ & $p$ value \\
\hline Age $($ years $)$ & $59.00(51.00-60.00)$ & $54.00(43.50-60.00)$ & 0.083 \\
\hline Weight $(\mathrm{kg})$ & $80.92 \pm 13.69$ & $70.10 \pm 13.11$ & 0.002 \\
\hline Waist Circumference $(\mathrm{cm})$ & $102.05 \pm 9.88$ & $92.81 \pm 11.45$ & 0.001 \\
\hline Hip Circumference $(\mathrm{cm})$ & $104.00(99.00-109.00)$ & $102.00(97.00-109.00)$ & 0.393 \\
\hline WHR & $0.97 \pm 0.04$ & $0.89 \pm 0.07$ & $<0.001$ \\
\hline WHtR & $0.61 \pm 0.06$ & $0.59 \pm 0.08$ & 0.398 \\
\hline BMI $\left(\mathrm{kg} / \mathrm{m}^{2}\right)$ & $27.68(25.86-30.85)$ & $28.35(24.27-31.97)$ & 0.733 \\
\hline SBP $(\mathrm{mm} \mathrm{Hg})$ & $125.16 \pm 13.14$ & $121.43 \pm 10.62$ & 0.242 \\
\hline DBP $(\mathrm{mm} \mathrm{Hg})$ & $79.92 \pm 6.38$ & $79.05 \pm 5.39$ & 0.575 \\
\hline FPG $(\mathrm{mg} / \mathrm{dl})$ & $144.00(121.00-167.00)$ & $106.00(88.50-151.50)$ & 0.002 \\
\hline 2hPPG $(\mathrm{mg} / \mathrm{dl})$ & $198.00(155.00-252.00)$ & $161.50(100.50-202.00)$ & 0.010 \\
\hline A1C $(\%)$ & $7.40(6.20-8.30)$ & $6.10(5.05-7.47)$ & 0.014 \\
\hline Plasma C-Peptide $(\mathrm{ng} / \mathrm{mL})$ & $2.65 \pm 1.20$ & $2.87 \pm 1.18$ & 0.711 \\
\hline FPI $(\mathrm{mU} / \mathrm{L})$ & $10.00(5.90-13.80)$ & $7.00(5.80-13.80)$ & 0.646 \\
\hline HOMA-IR & $3.54(2.18-4.56)$ & $1.96(1.45-4.05)$ & 0.031 \\
\hline HDL-C (mg/dl) & $40.63 \pm 9.46$ & $50.52 \pm 9.86$ & $<0.001$ \\
\hline LDL-C $(\mathrm{mg} / \mathrm{dl})$ & $98.70 \pm 27.36$ & $100.95 \pm 38.42$ & 0.770 \\
\hline Non-HDL-C $(\mathrm{mg} / \mathrm{dl})$ & $131.35 \pm 31.49$ & $137.62 \pm 47.96$ & 0.580 \\
\hline Triglycerides $(\mathrm{mg} / \mathrm{dl})$ & $151.00(115.00-177.00)$ & $115.00(89.00-244.00)$ & 0.269 \\
\hline Total Cholesterol $(\mathrm{mg} / \mathrm{dl})$ & $171.98 \pm 34.96$ & $188.14 \pm 48.14$ & 0.167 \\
\hline UAE (mg/day) & $12.00(5.65-28.00)$ & $12.00(2.80-26.00)$ & 0.689 \\
\hline Serum Creatinine & $1.11 \pm 0.19$ & $0.90 \pm 0.16$ & $<0.001$ \\
\hline Serum Uric Acid & $6.00 \pm 1.20$ & $5.09 \pm 1.13$ & 0.006 \\
\hline ALT (IU/L) & $28.50(22.00-39.00)$ & $20.00(15.25-25.25)$ & 0.002 \\
\hline AST $(\mathrm{IU} / \mathrm{L})$ & $22.00(17.75-28.00)$ & $20.00(16.00-24.50)$ & 0.127 \\
\hline ALKP $(\mathrm{IU} / \mathrm{L})$ & $127.85 \pm 63.65$ & $122.89 \pm 45.53$ & 0.760 \\
\hline GGT $(\mathrm{IU} / \mathrm{L})$ & $23.00(18.00-35.00)$ & $17.90(15.00-26.00)$ & 0.086 \\
\hline 25(OH)D & $14.95(8.21-19.75)$ & $23.00(9.50-29.50)$ & 0.062 \\
\hline hs-CRP & $1.00(1.00-1.22)$ & $0.90(1.00-2.45)$ & 0.862 \\
\hline Homocysteine & $10.88 \pm 3.14$ & $9.07 \pm 3.33$ & 0.054 \\
\hline Fibrinogen & $3.20 \pm 0.81$ & $3.21 \pm 0.70$ & 0.983 \\
\hline SHBG (nmol/L) & $35.60(28.00-50.00)$ & $45.00(33.50-71.86)$ & 0.022 \\
\hline
\end{tabular}


Table 2. Correlations Relating SHBG and Parameters of Metabolic Derangement

\begin{tabular}{|c|c|c|c|c|}
\hline & \multicolumn{2}{|c|}{$\operatorname{Men}(n=63)$} & \multicolumn{2}{|c|}{ Women $(n=21)$} \\
\hline & $r$ & $\begin{array}{l}p \\
\text { value }\end{array}$ & $r$ & $p$ value \\
\hline \multicolumn{5}{|l|}{ Central Obesity } \\
\hline $\begin{array}{l}\text { Waist } \\
\text { Circumference } \\
\text { (cm) }\end{array}$ & -0.296 & 0.018 & -0.144 & 0.534 \\
\hline BMI $\left(\mathrm{kg} / \mathrm{m}^{2}\right)$ & -0.270 & 0.032 & -0.256 & 0.263 \\
\hline \multicolumn{5}{|l|}{ Hyperglycemia } \\
\hline FPG (mg/dl) & 0.169 & 0.186 & -0.027 & 0.909 \\
\hline $2 \mathrm{hPPG}(\mathrm{mg} / \mathrm{dl})$ & 0.137 & 0.289 & 0.066 & 0.782 \\
\hline $\mathrm{A} 1 \mathrm{C}(\%)$ & 0.032 & 0.803 & -0.099 & 0.677 \\
\hline $\begin{array}{l}\text { Plasma C- } \\
\text { Peptide (ng/mL) }\end{array}$ & -0.179 & 0.382 & -0.600 & 0.285 \\
\hline FPI (mU/L) & -0.318 & 0.011 & -0.158 & 0.494 \\
\hline HOMA-IR & -0.262 & 0.038 & -0.101 & 0.662 \\
\hline \multicolumn{5}{|l|}{ Dyslipidemia } \\
\hline $\begin{array}{l}\text { HDL-C } \\
(\mathrm{mg} / \mathrm{dl})\end{array}$ & -0.094 & 0.464 & 0.154 & 0.505 \\
\hline LDL-C (mg/dl) & -0.260 & 0.040 & -0.156 & 0.500 \\
\hline $\begin{array}{l}\text { Non-HDL-C } \\
(\mathrm{mg} / \mathrm{dl})\end{array}$ & -0.330 & 0.008 & -0.030 & 0.898 \\
\hline $\begin{array}{l}\text { Total } \\
\text { Cholesterol } \\
(\mathrm{mg} / \mathrm{dl})\end{array}$ & -0.305 & 0.015 & 0.012 & 0.958 \\
\hline $\begin{array}{l}\text { Triglycerides } \\
(\mathrm{mg} / \mathrm{dl})\end{array}$ & -0.272 & 0.031 & -0.201 & 0.381 \\
\hline \multicolumn{5}{|l|}{ Hypertension } \\
\hline SBP (mmHg) & -0.033 & 0.795 & 0.099 & 0.669 \\
\hline DBP $(\mathrm{mmHg})$ & -0.120 & 0.350 & -0.264 & 0.248 \\
\hline \multicolumn{5}{|l|}{ Other Variables } \\
\hline Age (years) & 0.284 & 0.024 & 0.108 & 0.641 \\
\hline $\begin{array}{l}\text { Hip } \\
\text { Circumference } \\
(\mathrm{cm})\end{array}$ & -0.295 & 0.019 & -0.153 & 0.509 \\
\hline WHR & -0.089 & 0.486 & 0.010 & 0.964 \\
\hline WHtR & -0.324 & 0.010 & -0.279 & 0.220 \\
\hline UAE (mg/day) & -0.002 & 0.991 & N/A & N/A \\
\hline $\begin{array}{c}\text { Serum } \\
\text { Creatinine }\end{array}$ & -0.112 & 0.384 & 0.009 & 0.971 \\
\hline $\begin{array}{l}\text { Serum Uric } \\
\text { Acid }\end{array}$ & -0.232 & 0.068 & -0.018 & 0.945 \\
\hline $\begin{array}{r}\text { ALT } \\
(\mathrm{IU} / \mathrm{L})\end{array}$ & 0.008 & 0.953 & 0.029 & 0.905 \\
\hline $\begin{array}{r}\text { AST } \\
(\mathrm{IU} / \mathrm{L})\end{array}$ & 0.138 & 0.283 & 0.187 & 0.431 \\
\hline $\begin{array}{l}\text { ALKP } \\
\text { (IU/L) }\end{array}$ & 0.025 & 0.852 & -0.141 & 0.576 \\
\hline GGT (IU/L) & 0.022 & 0.879 & -0.455 & 0.160 \\
\hline $25(\mathrm{OH}) \mathrm{D}$ & 0.231 & 0.076 & 0.143 & 0.583 \\
\hline hs-CRP & -0.073 & 0.598 & 0.056 & 0.831 \\
\hline Homocysteine & -0.239 & 0.105 & -0.230 & 0.392 \\
\hline Fibrinogen & -0.237 & 0.122 & -0.046 & 0.875 \\
\hline
\end{tabular}

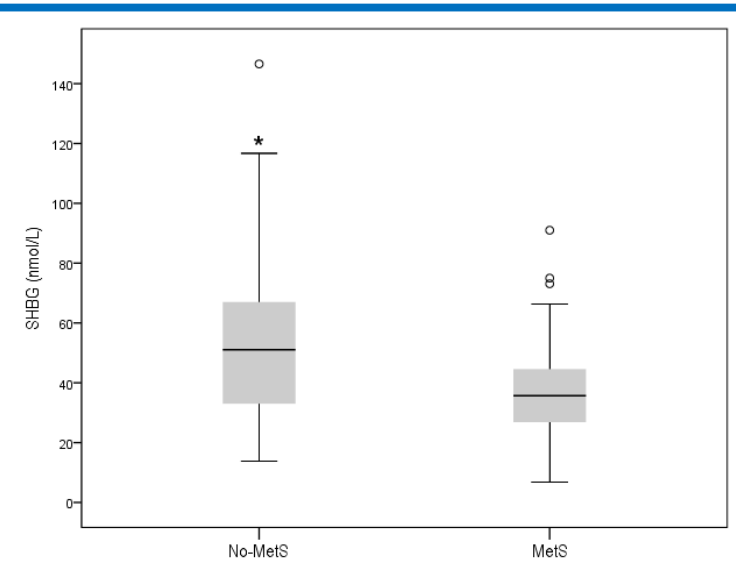

Fig 1. Comparison of Serum SHBG among People with or without the MetS in the Population Cohort. Error Bars Represent Standard Error of the Mean ( $p$ value $<0.05)$.

other laboratory parameters such as LDL-C, non-HDL$\mathrm{C}$, triglycerides, total cholesterol, and etc. between men and women.

Correlations Relating SHBG and Parameters of Metabolic Derangement

For determining the relations between serum concentration of SHBG and metabolic derangements, we investigated the relation between plasma levels of SHBG and others laboratory parameters with using Pearson correlation study. Table 2 shows that central obesity including waist circumference and BMI were significantly higher in men with lower plasma concentration of SHBG in compare to men with normal

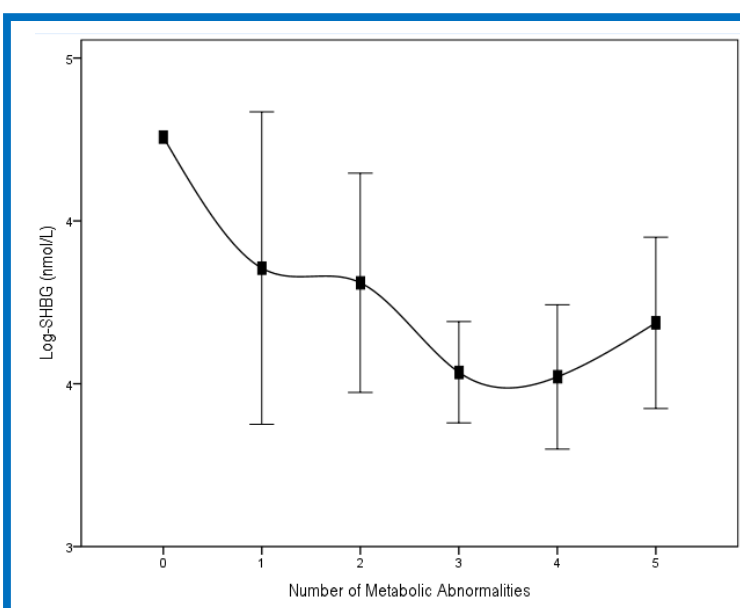

Fig 2. Association of Log-SHBG with The Number of Metabolic Abnormalities. Log-SHBG Values Is Not Significantly Decreased in Subjects with More Metabolic Abnormalities (0 to 5; ANOVA F: 1.354, p value for linear trend $=0.120$ ). 
Metabolic Syndrome and Sex Hormone-Binding Globulin

Eur J Transl Myol 29 (2): 143-150, 2019

Table 3. Logistic Regression Models for the Association of SHBG with the MetS and its individual components among Men and Women.

\begin{tabular}{|c|c|c|c|c|c|}
\hline & \multirow[t]{2}{*}{ Dependent Variable } & \multicolumn{2}{|l|}{ Crude Model } & \multicolumn{2}{|c|}{ Multivariate Adjusted Model } \\
\hline & & OR $(95 \% \mathrm{CI})$ & $p$ value & OR $(95 \%$ CI $)$ & $p$ value \\
\hline \multicolumn{6}{|l|}{$\begin{array}{l}\text { Men } \\
(n=63)\end{array}$} \\
\hline & Central Obesity & $0.958(0.911$ to 1.007$)$ & 0.095 & N/A & N/A \\
\hline & Raised Triglycerides & $0.976(0.945$ to 1.008$)$ & 0.145 & 0.987 (0.948 to 1.028$)$ & 0.534 \\
\hline & Reduced HDL-C & $1.004(0.974$ to 1.035$)$ & 0.777 & $0.992(0.951$ to 1.035$)$ & 0.715 \\
\hline & Raised Blood Pressure & $1.029(0.996$ to 1.064$)$ & 0.090 & $1.025(0.977$ to 1.077$)$ & 0.311 \\
\hline & Raised FPG & $1.020(0.925$ to 1.124$)$ & 0.695 & $\mathrm{~N} / \mathrm{A}$ & N/A \\
\hline & MetS & $0.976(0.941$ to 1.012$)$ & 0.181 & $0.948(0.883$ to 1.017$)$ & 0.135 \\
\hline \multicolumn{6}{|l|}{$\begin{array}{l}\text { Women } \\
(n=21)\end{array}$} \\
\hline & Central Obesity & $0.988(0.962$ to 1.016$)$ & 0.394 & N/A & N/A \\
\hline & Raised Triglycerides & $0.989(0.960$ to 1.019$)$ & 0.459 & N/A & N/A \\
\hline & Reduced HDL-C & $0.992(0.966$ to 1.019$)$ & 0.553 & +2 & N/A \\
\hline & Raised Blood Pressure & $0.995(0.968$ to 1.023$)$ & 0.732 & +2 & $\mathrm{~N} / \mathrm{A}$ \\
\hline & Raised FPG & $0.997(0.971$ to 1.024$)$ & 0.838 & N/A & $\mathrm{N} / \mathrm{A}$ \\
\hline & MetS & $0.977(0.944$ to 1.011$)$ & 0.182 & N/A & N/A \\
\hline
\end{tabular}

level of SHBG $(P<0.05)$. Also, the concentration of LDL-C $(P<0.05)$, non-HDL-C $(P<0.01)$, total cholesterol $(P<0.05)$, triglycerides $(P<0.05)$, serum creatinine $(P<0.05)$, FPI $(P<0.05)$ and HOMA-IR $(P<0.05)$ increased in men with higher plasma level of SHBG. On the other hand, we observed that older men with higher hip circumference and waist-to-height ratio (WHtR) have an abnormal level of SHBG $(P<0.05)$. One-way ANOVA analysis revealed that there is a significant deference in mean $\log$-SHBG value between individual with and without MetS $(P<0.05)$. Figure 1 shows that the individuals with MetS (without considering the genders) have a significantly lower mean $\log -\mathrm{SHBG}$ value in compare to healthy individuals $(P<0.05)$.

\section{Association between SHBG and MetS}

In the current work, results obtained from one-way ANOVA analysis shows that plasma concentration of SHBG (Log-SHBG) is not significantly decreased in subjects with more metabolic abnormalities $(P>0.05)$ (Figure 2). Five metabolic abnormalities including central obesity, raised FPG, reduced HDL-C, raised triglycerides and raised blood pressure are not significantly change in patients with lower plasma level of SHBG. In table 3, analysis demonstrated that there is no significant difference between the patients have lower plasma level of SHBG and the developing of MetS in them. In this regard, we investigated the five metabolic

Table 4. Multivariate Regression Analysis Determining the Significant Correlates of SHBG among Men and Women.

\begin{tabular}{|l|l|l|l|l|}
\hline & \multicolumn{2}{|l|}{ Men $(n=63)$} & \multicolumn{2}{l|}{ Women $(n=21)$} \\
\hline Variables & $\beta$ & $p$ value & $\beta$ & $p$ value \\
\hline Log-Age & 0.116 & 0.521 & N/A & N/A \\
\hline Log-Hip Circumference & -0.712 & 0.020 & N/A & N/A \\
\hline Log-BMI & 0.444 & 0.163 & N/A & N/A \\
\hline DBP & -0.037 & 0.813 & N/A & N/A \\
\hline Log-FPI & -0.639 & 0.035 & N/A & N/A \\
\hline Log-HOMA-IR & 0.443 & 0.133 & N/A & N/A \\
\hline Non-HDL-C & -0.296 & 0.028 & N/A & N/A \\
\hline Log-Triglycerides & -0.051 & 0.698 & N/A & N/A \\
\hline Serum Creatinine & -0.159 & 0.233 & N/A & N/A \\
\hline Log-25(OH)D & 0.301 & 0.527 & N & N \\
\hline Log-hs-CRP & 0.081 & & N \\
\hline
\end{tabular}


abnormalities which occur in patients with MetS, in individuals with a lower concentration of SHBG. The results show that there are no significant differences between lower plasma level of SHBG and metabolic abnormalities and finally MetS in both men and women $(P>0.05)$. As mentioned in table 4, Multivariate Regression Analysis among men and women determined that plasma level of SHBG is associated to Log-Hip Circumference, Non-HDL-C, and Log-25(OH)D $(P<0.05)$. On the other hand, no significant differences were seen between plasma level of SHBG and Log-Age, Log-BMI, DBP, Log-FPI, Log-HOMA-IR, Non-HDL-C, Log-Triglycerides, Serum Creatinine, Log-25(OH) D, and Log-hs-CRP when we investigated both men and women together $(P>0.05)$.

\section{Discussion}

In this study, we selected 84 middle-aged men and women randomly for our population. Our results revealed that SHBG levels were higher in women. In addition, we suggested that lower plasma level of SHBG could contributed to some laboratory parameters such as LDL$\mathrm{C}$, total cholesterol, triglycerides and etc. in men, but not in women. On the other hand, we observed that concentration of SHBG is higher in patients with MetS; however, results from our experiment showed that there is no relation between lower level of SHBG and five components of MetS such as central obesity, raised FPG, reduced HDL-C, raised triglycerides and raised blood pressure in both men and women. SHBG is a glycoprotein transporter in blood which involved in the circulating of sex steroids. ${ }^{14}$ The expression of this transporter modulated by several parameters such as the androgen/estrogen, glucocorticoids, insulin and etc. ${ }^{15-17} \mathrm{It}$ should be noted that the plasma level of SHBG is significantly lower in men. ${ }^{18}$ Numerous studies have shown that low plasma levels of SHBG associated with several components of the MetS in both men and women. ${ }^{19-21}$ It was suggest that low SHBG levels contributed to increase abdominal obesity, lipid profiles including higher triglyceride levels and lower highdensity lipoprotein (HDL)-cholesterol, hyper insulinemia, glucose intolerance or insulin resistance. ${ }^{22,23}$ Also, some studies showed that MetS could increase the risk of CVD and T2DM. ${ }^{24,25}$ Therefore, it could be concluded that SHBG levels could use as a predictor the development of diabetes or CVD, however, this conclusion is not in line with some studies. Laaksonen et al. showed that the risk of MetS has been increased at the lowest level of testosterone when compared to the highest. ${ }^{26,27}$ In line with mentioned study, others have reported that increasing in the levels of total testosterone and SHBG are related to decrease the risk of MetS dependently on age, smoking and BMI, ${ }^{28}$ however, the mechanism by which higher levels of SHBG might protect against the development of MetS is unclear. However, few studies failed to show any relation between testosterone and MetS. ${ }^{29}$ In this study, we observed that the patients who suffer from MetS have a lower plasma level of SHBG in compare to healthy population in both men and women. Nonetheless, some articles have shown that the plasma level of SHBG could be predictor for the MetS and its development. ${ }^{30}$ On the other hand, we observed that there is no significant relation between numbers of metabolic abnormalities and $\log$-SHBG value. These data suggest that although in MetS the plasma level of SHBG has been decreased, however, there is no significant association between development of MetS and SHBG concentration. On the other hand, for investigating the relation between SHBG and MetS in men and women separately, we compared the data obtained from men and women with lower level of SHBG with those with normal SHBG concentration. The results showed that there is no significant difference between those with lower and normal SHBG level in five components of metabolic abnormalities. It was hypothesized that SHBG and sex steroids such as testosterone are directly associated with metabolic abnormalities including HDL-cholesterol by increasing the hepatic production of apolipoprotein A-I, the major protein constituent of nascent high-density lipoprotein particles. ${ }^{31}$ Also, Low circulating levels of testosterone and subsequently low plasma level of SHBG were observed in obesity, which is accompanied by insulin resistance. ${ }^{32}$ These data supported that due to concentration of testosterone the metabolic abnormalities are higher men in compare to women, however some studies revealed that in premenopausal women the association between plasma concentration of SHBG and metabolic abnormalities is similar to which observed in men. ${ }^{18}$ Although, the significant association between SHBG and HDL cholesterol levels in men was seen in some studies, however, there are some articles which have revealed the conflicted results. ${ }^{33}$ The reasons for these controversies are unknown. Nevertheless, results from our present study suggest that the concentration of SHBG is mostly sex-depended, however, we observed abnormal lipid profile in men with lower level of SHBG such as increased in LDL-C, total cholesterol and triglycerides and decreased in non-HDL-C. Therefore, our results are in confirmation of previous articles which showed SHBG is associated with some of five components of MetS only in men. Although, our results are not in line with many articles which investigated the role of SHBG in MetS in men and women, however, the data obtained from analysis showed that there is a significant association between SHBG and Log-Hip Circumference, Non-HDL-C and Log-25(OH)D in both men and women.

In this study we demostrated that there is a relation between lower SHBG concentration and MetS, however, SHBG is not a powerful enough factor to use as a predictor of MetS alone. Also, there is no association between plasma level of SHBG and development of five components of MetS. In addition, this study suggest that lower SHBG level may contributed to lipid profiles. 


\section{Metabolic Syndrome and Sex Hormone-Binding Globulin}

Eur J Transl Myol 29 (2): 143-150, 2019

\section{List of acronyms}

CVD - cardiovascular disease

DHT - dihydrotestosterone

FI - Fasting insulin

HOMA-IR- Homeostatic model assessment of insulin

resistance

FPG - fasting plasma glucose

HDL-C - High-density lipoprotein cholesterol

HepG2 - hepatoma cell line

HbA1c - glycated hemoglobin

hsCRP - high sensitivity C-reactive protein

LDL - low-density lipoprotein

MetS - metabolic syndrome

SHBG - sex hormone-binding globulin

SUA - serum uric acid

T2DM - type 2 diabetes mellitus

\section{Authors contributions}

Amin Alinezhad, Design and conception and data collection. Fatemeh Jafari, Data analysis and writing of the paper.

\section{Acknowledgments None.}

Funding No funding for this research project.

\section{Conflict of Interest}

The authors declare they have no conflicts of interest..

\section{Ethical Publication Statement}

We confirm that we have read the Journal's position on issues involved in ethical publication and affirm that this report is consistent with those guidelines.

\section{Corresponding Author}

Fatemeh Jafari, Information Technology Engineering, Qazvin Branch, Islamic Azad University, Qazvin, Iran. Email: fatemehjafari2010@yahoo.com

\section{E-mail of co-author}

Amin Alinezhad: draminalinezhad@yahoo.com

\section{References}

1. Petra PH. The plasma sex steroid binding protein (SBP or SHBG). A critical review of recent developments on the structure, molecular biology and function. $\mathbf{J}$ Steroid Biochem Mol Biol 1991;40:735-53.

2. Plymate SR, Jones R, Matej L, Friedl K. Regulation of sex hormone binding globulin (SHBG) production in Hep G2 cells by insulin. Steroids 1988;52:339-40.

3. Haffner SM, Katz MS, Stern MP, Dunn JF. The relationship of sex hormones to hyperinsulinemia and hyperglycemia. Metabolism 1988;37:683-8.

4. Muller M, Van Der Schouw YT, Thijssen JH, Grobbee DE. Endogenous sex hormones and cardiovascular disease in men. J Clin Endocrinol Metab 2003;88:5076-86.
5. Muller M, van den Beld AW, Bots ML, et al. Endogenous sex hormones and progression of carotid atherosclerosis in elderly men. Circulation 2004;109:2074-9.

6. Le TN, Nestler JE, Strauss JF, Wickham EP. Sex hormone-binding globulin and type 2 diabetes mellitus. Trends Endocrinol Metab 2012;23:32-40.

7. Reaven GM. Role of insulin resistance in human disease. Diabetes 1988;37:1595-607.

8. Liese AD, Mayer-Davis EJ, Haffner SM. Development of the multiple metabolic syndrome: an epidemiologic perspective. Epidemiol Rev 1998;20:157.

9. Laaksonen DE, Lakka H-M, Salonen JT, et al. Low levels of leisure-time physical activity and cardiorespiratory fitness predict development of the metabolic syndrome. Diabetes care 2002;25:16128.

10. Phillips GB. Sex hormones, risk factors and cardiovascular disease. Am J Med 1978;65:7-11.

11. Lakka H-M, Laaksonen DE, Lakka TA, et al. The metabolic syndrome and total and cardiovascular disease mortality in middle-aged men. JAMA 2002;288:2709-16.

12. Phillips GB. Relationship between serum sex hormones and the glucose-insulin-lipid defect in men with obesity. Metabolism 1993;42:116-20.

13. Reusch JE. Current concepts in insulin resistance, type 2 diabetes mellitus, and the metabolic syndrome. Am J Cardiol 2002;90:19-26.

14. Anderson DC. Sex-hormone-binding globulin. Clin Endocrinol (Oxf) 1974;3:69-96.

15. Rosner W. Plasma steroid-binding proteins. Endocrinol Metab Clin North Am 1991;20:697720.

16. Hautanen A, Sarna S, Pelkonen R, Adlercreutz H. Serum sex hormone-binding globulin, cardiovascular risk factors, and adrenal cortisol responses to dexamethasone and corticotropin. Metabolism 1993;42:870-4.

17. Plymate SR, Matej LA, Jones RE, Friedl KE. Inhibition of Sex Hormone-Binding Globulin Production in the Human Hepatoma (Hep G2) Cell Line by Insulin and Prolactin. J Clin Endocrinol Metab 1988;67:460-4.

18. Hajamor S, Després J-P, Couillard C, et al. Relationship between sex hormone-binding globulin levels and features of the metabolic syndrome. Metabolism 2003;52:724-30.

19. Tchernof A, Toth MJ, Poehlman ET. Sex hormonebinding globulin levels in middle-aged premenopausal women. Associations with visceral obesity and metabolic profile. Diabetes Care 1999;22:1875-81.

20. Tchernof A, Després J-P. Sex steroid hormones, sex hormone-binding globulin, and obesity in men and women. Horm Metab Res 2000;32:526-36. 
21. Pugeat $\mathrm{M}$, Moulin $\mathrm{P}$, Cousin $\mathrm{P}$, et al. Interrelations between sex hormone-binding globulin (SHBG), plasma lipoproteins and cardiovascular risk. The $\mathrm{J}$ Steroid Biochem Mol Biol 1995;53:567-72.

22. Goodman-Gruen D, Barrett-Connor E. Sex hormone-binding globulin and glucose tolerance in postmenopausal women: the Rancho Bernardo Study. Diabetes Care 1997;20:645-9.

23. Sherif K, Kushner H, Falkner BE. Sex hormonebinding globulin and insulin resistance in AfricanAmerican women. Metabolism 1998;47:70-4.

24. Haffner SM, Katz MS, Stern MP, Dunn JF. Association of decreased sex hormone binding globulin and cardiovascular risk factors. Arteriosclerosis 1989;9:136-43.

25. Haffner SM, Valdez RA, Morales PA, et al. Decreased sex hormone-binding globulin predicts noninsulin-dependent diabetes mellitus in women but not in men. J Clin Endocrinol Metab 1993;77:56-60.

26. Laaksonen DE, Lakka H-M, Niskanen LK, et al. Metabolic syndrome and development of diabetes mellitus: application and validation of recently suggested definitions of the metabolic syndrome in a prospective cohort study. Am J Epidemiol 2002;156:1070-7.

27. Laaksonen DE, Niskanen L, Punnonen K, et al. Testosterone and sex hormone-binding globulin predict the metabolic syndrome and diabetes in middle-aged men. Diabetes care 2004;27:1036-41.

28. Muller M, Grobbee DE, Den Tonkelaar I, et al. Endogenous sex hormones and metabolic syndrome in aging men. $\mathbf{J}$ Clin Endocrinol Metab 2005;90:2618-23.

29. Kupelian V, Page ST, Araujo AB, et al. Low sex hormone-binding globulin, total testosterone, and symptomatic androgen deficiency are associated with development of the metabolic syndrome in nonobese men. J Clin Endocrinol Metab 2006;91:843-50.

30. Birkeland KI, Hanssen KF, Torjesen PA, Vaaler S. Level of sex hormone-binding globulin is positively correlated with insulin sensitivity in men with type 2 diabetes. J Clin Endocrinol Metab1993;76:275-8.

31. Zmuda JM, Cauley JA, Kriska A, et al. Longitudinal relation between endogenous testosterone and cardiovascular disease risk factors in middle-aged men a 13-year follow-up of former multiple risk factor intervention trial participants. Am J Epidemiol 1997;146:609-17.

32. Marin P, Arver S. Androgens and abdominal obesity. Baillieres Clin Endocrinol Metab 1998;12:441-51.

33. Goodman-Gruen D, Barrett-Connor E. A prospective study of sex hormone-binding globulin and fatal cardiovascular disease in Rancho Bernardo men and women. J Clin Endocrinol Metab 1996;81:2999-3003.

Submissions: April, 01, 2019

Revision received: May 17, 2019

Acceptance: May 17, 2019 